\title{
Atypische Athetosis.
}

\author{
Von \\ Dr. G. Flatau, \\ Nervenarzt. \\ Nach einer Demonstration im Neurol.-Psych. Verein in Berlin \\ (aus der Nervenstation des Res.-Laz. Kunstgewerbemuseum. \\ Chefarzt; Oberstabsarzt Dr. Bernheim). \\ Mit 2 Textfiguren.
}

(Eingegangen am 28. Mai 1917.)

Im Lazarett Kunstgewerbemuseum wurde der jetzt 26 jährige Pionier zuerst ambulant und später stationär beobachtet. Das Leiden des Mannes bietet in differentialdiagnostischer Hinsicht Interesse. Der Mann stammt aus einer gesunden Familie. Die Eltern sind am Leben. Der Vater hat mit Giften nichts zu tun gehabt, soll auch nicht getrunken haben. Die Anamnese bleibt etwas unvollkommen, es ist keine Angabe darüber zu erhalten, ob die Entbindung schwierig gewesen ist und $o b$ in frühester Jugend fieberhafte Erkrankungen vorgekommen sind. Der Mann selbst will wissen, daß er niemals, auch als Kind nicht, Krämpfe gehabt hat, daß er früh sprechen, aber erst mit drei Jahren gehen lernte; er sei als Kind unbeholfen gewesen, was sich besonders beim Greifen bemerkbar machte. Ein abnormes Sprechen will er nicht bemerkt haben, in der Schule sei er nicht schlecht mitgekommen, er habe zwar einen eigentlichen Beruf nicht erlernt, habe aber seinem Vater in der Tischlerei und in der Spargelfeldbewirtschaftung ausreichend helfen können. Nach seiner Einziehung zum Militärdienst habe er nur wenige Tage einfachen Dienst gemacht, da er durch die Unbeholfenheit seiner Bewegungen auffiel und namentlich die Hand beim Grüßen nicht recht an den Kopf bringen konnte (Fig. 1); auch schneller Schritt gelang ihm nicht.

Bei der Untersuchung des Mannes fällt zunächst die abnorme Stellung des Mundes auf, dieser ist nach links verzogen, beim Öffnen des Mundes wird das noch deutlicher. In der Ruhe sieht man ein Zucken und Zittern der linken Gesichtshälfte. Beim Sprechen kommt es zu starker Anspannung der vordern Halsmuskulatur, das Kinn wird an die Halswirbelsäule gepreßt, Das Anlauten braucht eine geraume Zeit, die Sprache hat einen gequetschten Charakter. Weiterhin stellt sich dabei noch eine Reihe von Mitbewegungen der Gesichtsmuskeln ein, so daß ein Grimassieren entsteht und die Verziehung des Mundes nach links sich noch verstärkt. Zuweilen gerät schon in der Ruhe die rechte Schultermuskulatur, speziell der Cucullaris in eine Contractur. wodurch die Schulter nach vorn und oben gezogen wird (Fig. 2). Beim 
Stchen sicht man solche Muskelspannungen im Supraspinatus, wodurch cine derartige Fellenbildung entsteht, daß man anfangs den Eirr!ruck eincr unschricbenen Atrophie hat; ferner im Deltoideus, in der Rückenlängsmuskulatur, in den Glutäen. Die Hände sind außerordentlich groß und kolbig gestaltet, die Greifbewegungen langsam und urgeschickt, dic einzelnen Fingerbewegungen langsam und schwerfäil.g, die grobe Kraft ist gut, in keiner Muskelgruppe kann man von eincr Herabsetzung der Kraftleistung sprechen. Das Gehen ist von ciner eigentïmlichen Gestaltung des Rumpfes begleitet: es kommt zu einer Lordose, $\mathrm{zu}$ einem Nachhintenwerfen des Kopfes und besondcrer

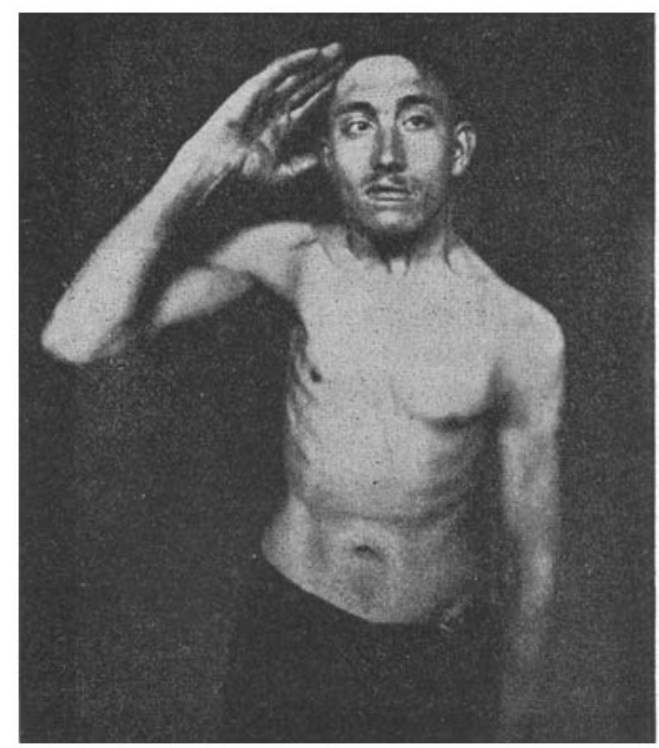

Fig. 1.

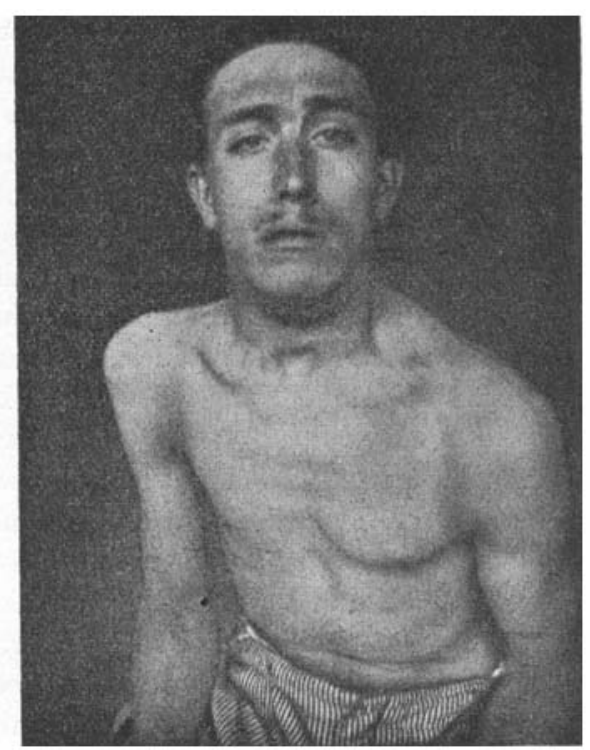

Fig. 2.

Hcbung und Senkung des Beckens. Dabei tritt außer der Hebung der Schultern auch eine Mitbewegung in Form einer starken Dorsalflexion der Zehen ein. Diese letztere ist auch im Liegen vorhanden und tritt in der Ruhe auf, begleitet aber auch die Bewegung entfernter Körpertelle, wic Faustballen, Öffnen des Mundes.

Die mechanische Muskelerregbarkeit ist gesteigert, die Knic- und Achillesphänomene sind gesteigert, der Zehenreflex ist unbestimmt, aber doch meistens plantar, überhaupt fehlt jedes Zeichen echter Spasmen, sensible Störungen fehlen. Der linke Bulbus steht dem unnern Augenwinkel genähert, beim Blick nach links erreicht er den äußern Augenwinkel nicht ganz. In allen seitlichen Endstellungen der Bulbi tritt Nystagmus auf. Bei all diesen Störungen war der Mann doch imstancle, selbst Näharbeit zu leisten und konnte auch sonst mit 
Arbeiten außerhalb des Lazaretts beschäftigt werden. Seine Intelligenz zeigte keine Störungen. Es ist noch anzuführen, daß der Mann behauptet, daß die jetzige Sprachstörung sich erst während der wenigen Tage, die er Dienst getan hat, so gestaltet hat, wie sie jetzt ist.

Zusammenfassend ist also zu sagen: es handelt sich um einen jetzt 26 jährigen Mann, der aus gesunder Familie stammt, und ohne daß eine erkennbare Gelegenheitsursache nachweisbar ist, in frühester Jugend eine Erschwerung der Bewegungen zeigt, so daß er erst spät laufen lernt. Die Angabe, daß die Sprachstörung früher nicht aufgefallen sei und sich erst beim Militär entwickelt habe, muß auf erhebliche Zweifel stoßen. Es wird sich damit verhalten, wie mit der von Anfang an vorhandenen Unbeholfenheit, die erst bei den stärkeren Anforderungen des Militärdienstes auffallender wurde. Die Krankheitserscheinungen sind also in früheste: Kindheit erworben oder sie waren angeboren. Das Charakteristische liegt in den ungewollten Muskelbewegungen, die in der Ruhe gering sind, so daß sie bei der Musterung gar nicht aufgefallen $\mathrm{zu}$ sein brauchen, die bei gewollten Bewegungen stärker werden, so daß sie störend wirken, die Sprache beeinträchtigen und der Haltung beim Gehen ein eigentümliches Gepräge geben. Die Art der ungewollten Bewegungen, ihr Verlauf, stellt sie den athetotischen am nächsten. Doch ist es nicht ganz leicht, das vorliegende Krankheitsbild zu klassifizieren. Von dem gewöhnlichen Bilde der Diplegia spastico-athetotica unterscheidet es sich außer durch die Art der Entstehung durch die Lokalisation der Bewegungen, durch die Geringfügigkeit derselben, durch das Fehlen der so charakteristischen Finger- und Zehenbewegungen und der Spasmen. Die Betätigung ist nicht in so hohem Grade behindert. Der Athétose double nähert sich das bei diesem Manne vorliegende Leiden am meisten. Doch ist das im ganzen unsymmetrische Verhalten der Bewegungen auffällig, auch handelt es sich nicht allein um Mitbewegungen, sondern auch solche, die in der Ruhe auftreten. Gleich bei der ersten Untersuchung erinnerte die Haltung beim Gehen doch an die Bilder der Dystonia musculorum (Oppenheim) und die Distorsionsneurose (Ziehen). Angedeutet ist die Lordose, bemerkenswert die vorwiegende Beteiligung der Rumpfmuskeln, das Fehlen von echten Spasmen, das Zurücktreten der ungewollten Bewegungen in der Ruhe.

Ich möchte das Leiden hier als eine atypische Form der Athétose double deuten, welches mit den von Lewandowsky beschriebenen Fällen weitgehende Ähnlichkeit aufweist. Die nahe Verwandtschaft dieser Bilder mit den oben crwähnten wird auch durch diesen Fall erwiesen.

Schließlich weist hier das Verhalten des Facialis und des linken Bulbus wohl darauf hin, daß die Grundlage in einer angeborenen oder früh erworbenen cerebralen Veränderung zu suchen ist. 